\title{
Secretory Behavior of Salivary Glands of Rhipicephalus sanguineus Fed on Immunized Rabbit Hosts
}

\author{
Karim Christina Scopinho Furquim*, Maria Izabel Camargo Mathias, Letícia Maria Gráballos Ferraz Hebling, Gislaine Cristina Roma and \\ Gervásio Henrique Bechara \\ UNESP, Av. 24 A, no 1515, Cx. Postal 199, CEP: 13506-900, Rio Claro, S.P., Brazil
}

\begin{abstract}
The histochemical analysis of the salivary glands of Rhipicephalus sanguineus females (Latreille, 1806) (Acari, Ixodidae) fed for 2, 4 and 6 days (test group $=\mathrm{TG}$ ) on hosts (New Zealand White rabbits) previously immunized with glandular extract of salivary glands obtained from females fed for 6 days (SGE6) was carried out in order to detect alterations in the secretion of glycoproteins, lipoproteins, acid phosphatase and calcium. It was here verified that the composition of the secretion produced by the glands of females from TG (2-6 days) was different from the one observed in those from control group (CG), with a gradual reduction in the synthesis of the components as feeding progressed, except for the proteins and calcium, which remained unaltered within the interval of 4 to 6 days and 2 to 4 days respectively. In the glands of females fed for 2 days (TG) there was increase in calcium staining, as well as a reduction in lipids and acid phosphatase, and staining for proteins and polysaccharides remained unaltered. In the females fed for 4 days (TG) there was a reduction in the intensity of staining of components, presenting an increase only for polysaccharides and calcium remained unaltered. In the glands of females fed for 6 days (TG) there was a reduction in the synthesis of the components, with an increase in proteins and calcium. Contrary to expected, it was verified that the alterations were more significant in the glands of females fed for 2 days than in the ones fed for 6 days, once the hosts were inoculated with antigens of the glandular tissue obtained from females fed for 6 days. In addition, it was verified that during the secretory cycle of glands from TG (2-6 days) $a, c 2, c 5, d$ and $f$ cells were the ones which presented the most histochemical alterations.
\end{abstract}

Keywords: Salivary gland extract; Immunization, Modulation of the host reaction; Immune-inflammatory and hemostatic systems; Histochemistry

\section{Introduction}

The ticks are extremely successful obligatory hematophage organisms, due to the adaptation of their salivary glands to the production of saliva with a high capability to modulate the immuneinflammatory and hemostatic systems of the infested host [1-8].

The meaning of hematophagy for the hosts goes beyond the spoliative action of the ectoparasite, being also related with the vehiculation of pathogenic agents due to the immunosuppressing properties of the ticks' saliva [9-11].

In the tick-host relationship it is verified that the saliva of the ectoparasite undergoes alterations in its composition [12-14], consequence of the alterations in the secretory behavior of its own secretory glands, which occurs in order to modulate the host according to the ectoparasite's needs [15].

In the case of $R$. sanguineus females, whose blood feeding occurs in the period of 7-8 days, their salivary glands undergo alterations throughout the process. Such glands comprise acini I, II and III, and the latter two undergo the most alterations, once they act in the feeding and osmoregulation processes in the phase of high blood consumption [16]. In the salivary glands of fasting females $a, c 1, c 3, d$ and $e$ cells are present. In those fed for 2 days $b, c 2, c 4, c 5, c 6$ and $f$ cells are activated; in those fed for 4 days $c 5$ and $c 6$ cells start to lose activity and $f$ cells became inactive from the secretory point of view; in the individuals fed for 6 days the glands are already in degeneration; and $b, c 5$ and $c 6$ cells are completely inactive [17].

However, it is known that the feeding by $R$. sanguineus female ticks on previously immunized hosts alters the secretory behavior according to the composition of the extract used for the immunization of the hosts. In this sense, an inactivity of some cellular types is verified, as well as precocious degeneration of the gland as a whole, events which occur to compensate the resistance acquired by the immunized hosts and allow the ticks' complete blood feeding [16].

Thus, the present study had the objective to histochemically follow the secretory cycle of $R$. sanguineus females fed for 2, 4 and 6 days on rabbits previously immunized with extracts of salivary glands from females of the same species fed for 6 days (SGE6).

Thus, the present study aimed to evaluate the histochemical changes in the secretory cycle of $R$. sanguineus females fed for 2, 4 and 6 days on rabbits previously immunized with extracts of salivary glands obtained from females of the same species fed for 6 days (SGE6) using techniques for detection of proteins, polysaccharides, lipids, acid phosphatase and calcium.

\section{Material and Methods}

\section{Materials}

To perform this study salivary glands of adult $R$. sanguineus females fed for 2, 4 and 6 days subjected to infestation on New Zealand White

*Corresponding author: Karim Christina Scopinho Furquim, UNESP, Av. 24 A, n 1515, Cx. Postal 199, CEP: 13506-900, Rio Claro, S.P., Brazil, Tel: 5519 35264151; Fax: +55 19 35340009; E-mail: karimfurquim@yahoo.com.br

Received September 22, 2014; Accepted November 07, 2014; Published November 09, 2014

Citation: Furquim KCS, Camargo-Mathias MI, Hebling LMGF, Roma GC, Bechara GH (2014) Secretory Behavior of Salivary Glands of Rhipicephalus sanguineus Fed on Immunized Rabbit Hosts. J Cytol Histol S4: 012. doi:10.4172/2157-7099.S4-012

Copyright: ( 2014 Furquim KCS, et al. This is an open-access article distributed under the terms of the Creative Commons Attribution License, which permits unrestricted use, distribution, and reproduction in any medium, provided the original author and source are credited. 
rabbits immunized with glandular extract of females fed for 6 days were used. For this, unfed individuals (males and females) from a colony kept in BOD incubator, in controlled conditions $\left(29^{\circ} \mathrm{C}, 80 \%\right.$ of humidity and photoperiod of 12 hours), in the Biotery of the Biology Department of UNESP campus Rio Claro (SP) were used in the infestations A, B e C made in rabbits according to the procedure described in the literature [18].

Infestation A: made in naive rabbits using 25 couples of $R$. sanguineus couples/host, for the acquisition of females of ticks fed for 6 days (25 individuals), for the obtainance of glandular extract: SGE6= glandular extract of females fed for 6 days.

The extract was processed and inoculated in the hosts subjected to infestation B.

Infestation B (test group $=$ TG): was made in 4 rabbits sensibilized with SGE6 extract, which were subjected to challenge infestation with 15 couples of adult $R$. sanguineus ticks/host.

Infestation $\mathbf{C}$ (control group= CG): was made in 4 naive rabbits that were not inoculated, which were subjected to challenge infestation with 15 couples of adult $R$. sanguineus ticks/host.

This experiment was approved by the Ethics Committee in Research and Scientific Merit- UNIARARAS, Protocol nº 021/2009.

\section{Methods}

Obtaining Salivary Glands and EGS6 Glandular Extract: In the Laboratory of the Department of Molecular Biology of UNESP Rio Claro (SP), Brazil, the salivary glands were put in eppendorf tube containing $200 \mu \mathrm{L}$ of phosphate buffer $\mathrm{pH}$ 7.4. Then the glands were macerated, centrifuged for 30 minutes at $10.000 \mathrm{xg}$, the supernatant was collected and was put for proteins dosage, which occurred according to the methodology described in the literature [19] (Bradford method), which should be of at least $0.2 \mu \mathrm{g} / \mu \mathrm{L}$.

After the determination of the protein content, the extract was filtered with the help of sterile filtering units (JBR610303, disposable filtering unit Millex GV, durapore membrane PVDF, Millipore, MilliUni), of $0.22 \mu \mathrm{m}$ and $13 \mathrm{~mm}$ of diameter, attached to hypodermic syringes in the interior of a pre-sterile vertical laminar flow. The extract was then divided in volumes of $50 \mu \mathrm{L}$ and kept in freezer at $-20^{\circ} \mathrm{C}$. Only at the moment of inoculation the extract was mixed $(50 \mu \mathrm{L}$ of extract/ host) with $50 \mu \mathrm{L}$ of complete Freund adjuvant (reference \# F 5881, Sigma-Aldrich), procedures that are also made in pre-sterile vertical laminar flow.

Immunization of Rabbits Hosts and Realization of the Challenge Infestation: After, rabbits from TG had the right dorsal side sheared and were subcutaneously inoculated with SGE6 extract, via hypodermic syringe, for three times in intervals of 21 days. Only after 15 days from the last inoculation, all the hosts from TG and CG were subjected to infestation challenge with 15 couples of $R$. sanguineus/host.

In the sequence, $R$. sanguineus females fed for 2, 4 and 6 days were removed from the rabbits inoculated with SGE6 extract (GT), as well as from those not inoculated (CG) and subjected to histochemistry analysis.

Histochemical Analyses: In the Histology Laboratory of the Biology Department of UNESP campus Rio Claro (SP), Brazil, salivary glands of $R$. sanguineus females of each group (TG and CG) fed for 2, 4 and 6 days were removed in buffered saline solution $(7.5 \mathrm{~g} \mathrm{NaCl}+$ $2.38 \mathrm{~g} \mathrm{Na}_{2} \mathrm{HPO}_{4}+2.72 \mathrm{~g} \mathrm{KH}_{2} \mathrm{PO}_{4}$ in $1000 \mathrm{~mL}$ distilled water) and fixed.
Part of the material was fixed in $4 \%$ paraformaldehyde at $4^{\circ} \mathrm{C}$, after fixation, the material was dehydrated in a series of increasing concentrations of ethanol $(70 \%, 80 \%, 90 \%$ and $95 \%)$, embedded in resin (Leica), and sectioned at $3 \mu \mathrm{m}$ thickness. Sections were mounted on glass slides and histochemical tests were applied to detect the presence of the following compounds: proteins (bromophenol blue) [20]; polysaccharides (PAS- Periodic Acid Schiff) [21]; calcium (von Kossa) [22] and lipids [23].

The other part of the material was fixed in $10 \%$ buffered neutral formalin and acetone (9:1) for one hour and thirty minutes at $4^{\circ} \mathrm{C}$, then processed according to the methods described by literature [24] for detection of acid phosphatase activity. The material was then dehydrated in increasing concentrations of ethanol (70\%, 80\%, $90 \%$ and $95 \%$ ), embedded in resin (Leica), and sectioned at a thickness of $7 \mu \mathrm{m}$. The sections were placed on glass slides and counterstained with hematoxylin for 2 minutes. The control samples were incubated without substrate.

The slides of the all histochemical tests were mounted with Canada balsam and examined and photographed under Motic BA 300 light microscope.

\section{Results}

Acini I were not considered in the analysis of salivary glands of the control group (CG) and test (TG), once they are agranular and do not have a secretory function, acting exclusively on the hydric balance of the ectoparasite [25-26].

\section{Control Group (CG)}

The histochemical data for the salivary glands of R.sanguineus females fed for 2, 4 and 6 days from the control group (CG) were presented in study realized previously [27].

\section{Test Group}

\section{Females fed for 2 days}

\section{Acinus II:}

- $\boldsymbol{a}$ cells: the granules are moderately stained for bromophenol blue (Figure $1 \mathrm{~A}-\mathrm{C}$ ) and Baker (Figure 3A-B); negative (Figure 2A and 2D) or weakly (Figure $2 \mathrm{~B}$ and $2 \mathrm{C}$ ) stained for PAS; negative for acid phosphatase (Figure 4A-E); and negative (Figure 5A), weakly (Figure $5 \mathrm{D}-\mathrm{E}$ ) stained or presenting heterogeneous staining (negative in one region and moderately stained in other) (Figure 5B and 5C) for von Kossa.

- $\boldsymbol{c} 1$ cells: are not observed for being inactive.

- $\mathbf{c} 2$ cells: the granules are weakly stained for bromophenol blue (Figure 1B) and Baker (Figure 3B and 3D); moderately stained for PAS (Figure 2C-D); weakly (Figure 4A) or moderately (Figure 4B) stained for acid phosphatase, and negative for von Kossa (Figure 5D).

- $c 3$ cells: the granules are moderately stained for bromophenol blue (Figure 1A and 1B) and acid phosphatase (Figure 4C); strongly stained for PAS (Figure 2B and 2C), Baker (Figure 3B-D) and von Kossa (Figure 5E).

- $c 4$ cells: the granules are negative to all the applied techniques (Figures 1C, 2D, 3A, 3D and 5F), except for acid phosphatase, where such cells are not observed.

- $\boldsymbol{c 5}$ cells: the granules are weakly stained for bromophenol blue (Figure 1B); weakly (Figure 2A and 2D) or moderately (Figure 2A) 
Citation: Furquim KCS, Camargo-Mathias MI, Hebling LMGF, Roma GC, Bechara GH (2014) Secretory Behavior of Salivary Glands of Rhipicephalus sanguineus Fed on Immunized Rabbit Hosts. J Cytol Histol S4: 012. doi:10.4172/2157-7099.S4-012

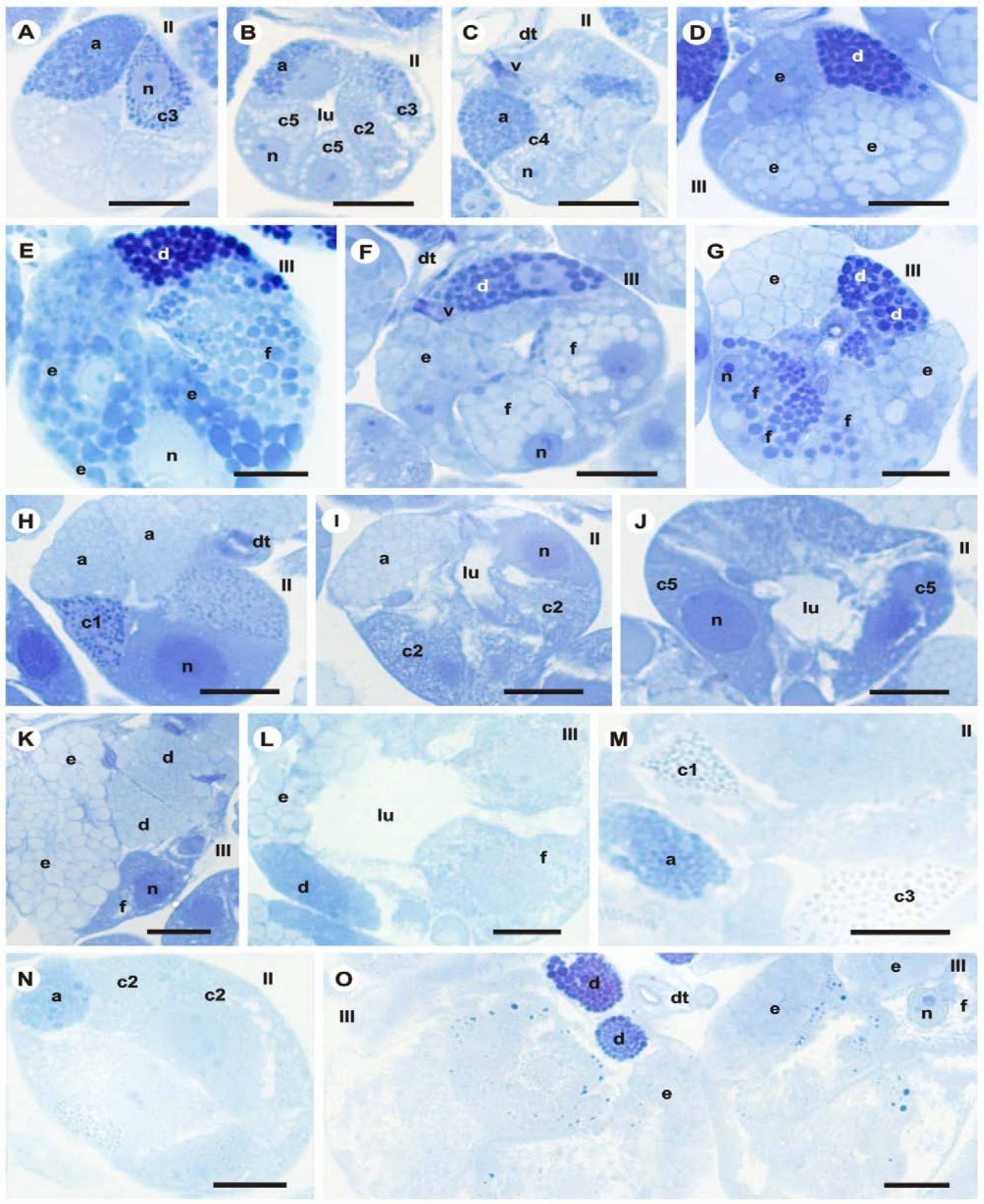

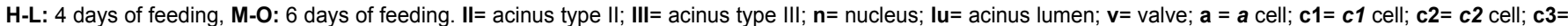
c3 cell; $\mathbf{c} 4=\mathbf{c} 4$ cell; $\mathbf{c} 5=\mathbf{c} 5$ cell; $\mathbf{d}=\boldsymbol{d}$ cell; $\mathbf{e}=\mathbf{e}$ cell, $\mathbf{f}=\boldsymbol{f}$ cell. Bars: $25 \mu \mathrm{m}$

Figure 1: Histological sections of salivary glands of Rhipicephalus sanguineus females used as test group TG (SGE6). Bromophenol blue technique. A-G: 2 days of feeding. 
Citation: Furquim KCS, Camargo-Mathias MI, Hebling LMGF, Roma GC, Bechara GH (2014) Secretory Behavior of Salivary Glands of Rhipicephalus sanguineus Fed on Immunized Rabbit Hosts. J Cytol Histol S4: 012. doi:10.4172/2157-7099.S4-012

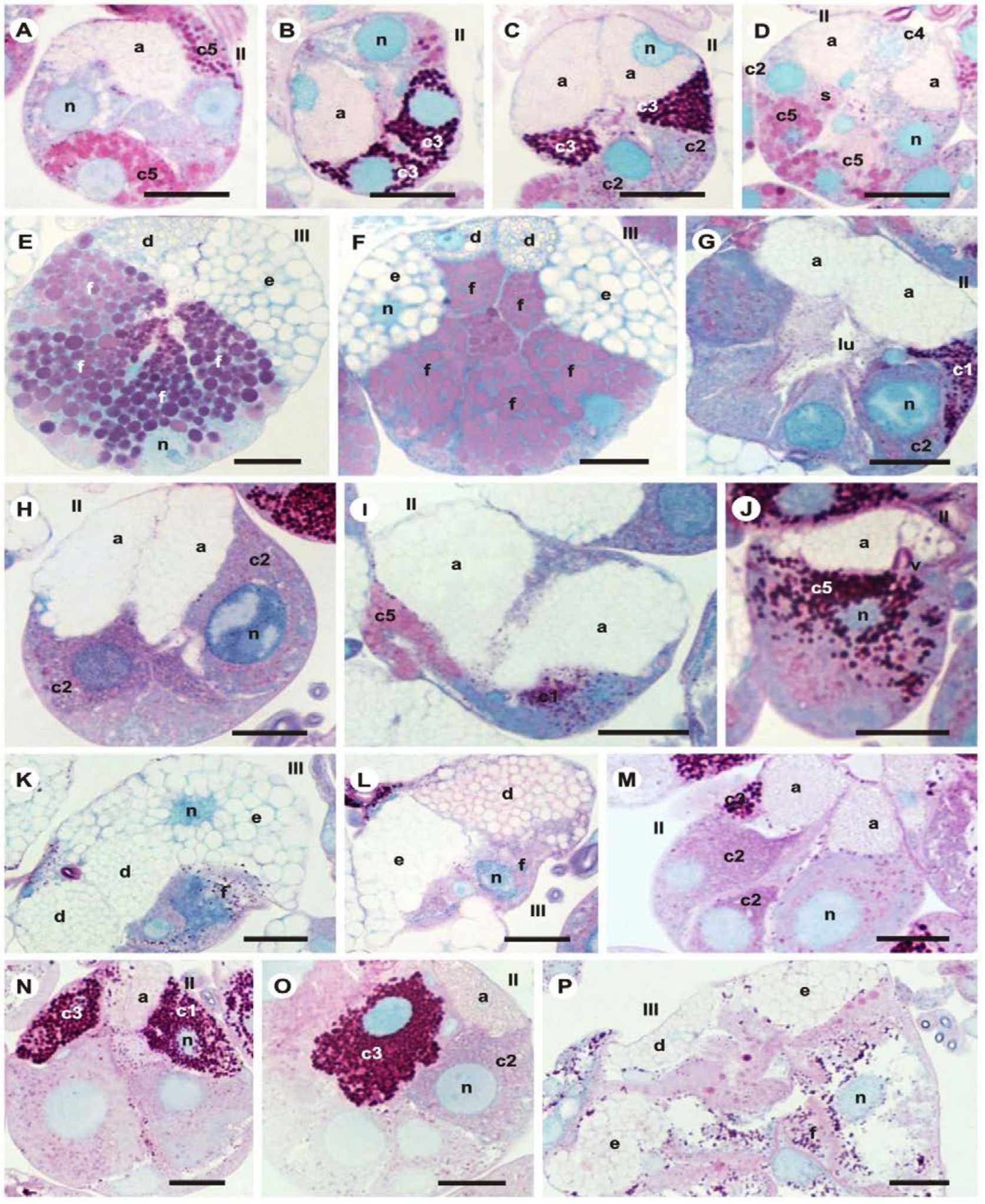

A-F: 2 days of feeding, G-L: 4 days of feeding, $\mathbf{M - P :} 6$ days of feeding. II= acinus type II; III= acinus type III; $\mathbf{n =}$ nucleus; $\mathbf{s}=\mathbf{s e c r e t i o n}$ granules; lu= acinus lumen; $\mathbf{v}=$ valve; $a=a$ cell; $c 1=c 1$ cell; $c 2=c 2$ cell; $c 3=c 3$ cell; $c 4=c 4$ cell; $c 5=c 5$ cell; $d=d$ cell; $e=e$ cell, $f=f$ cell. Bars: $25 \mu m$

Figure 2: Histological sections of salivary glands of Rhipicephalus sanguineus females used as test group TG (SGE6). PAS reaction and counterstained with methyl green. 


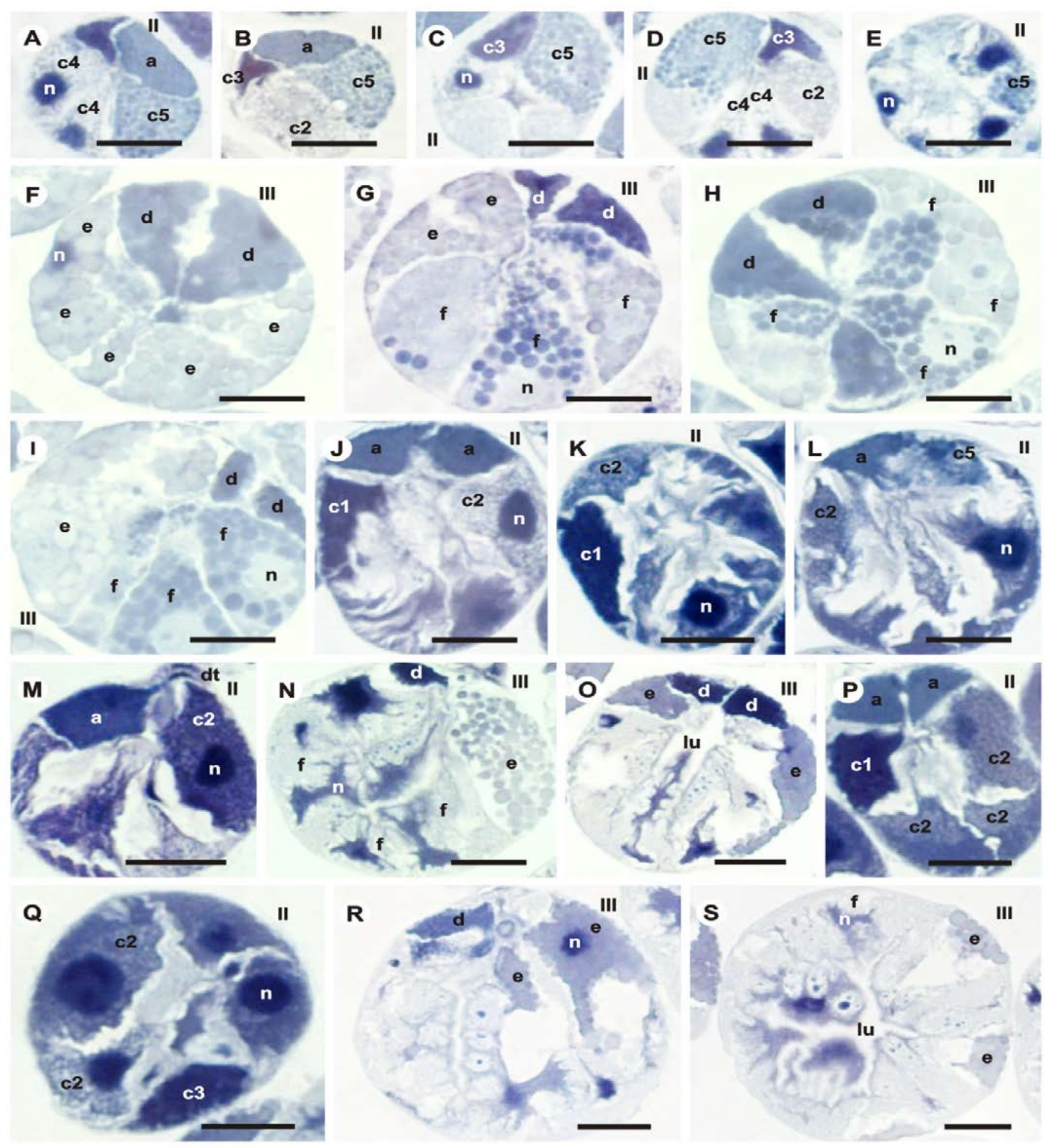

A-I: 2 days of feeding, J-O: 4 days of feeding, P-S: 6 days of feeding. II= acinus type II; III= acinus type III; $\mathbf{n =}$ nucleus; lu= acinus lumen; $\mathbf{d t =}$ ducto; $\mathbf{a}=\mathbf{a}$ cell; $\mathbf{c} \mathbf{1}=\mathbf{c 1}$ cell; $\mathbf{c} 2=\boldsymbol{c} \mathbf{2}$ cell; $\mathbf{c} \mathbf{3}=\mathbf{c} \mathbf{3}$ cell; $\mathbf{c} \mathbf{4}=\mathbf{c} \mathbf{4}$ cell; $\mathbf{c} 5=\boldsymbol{c} \mathbf{5}$ cell; $\mathbf{d}=\boldsymbol{d}$ cell; $\mathbf{e}=\mathbf{e}$ cell, $\mathbf{f}=\boldsymbol{f}$ cell. Bars: $25 \mu \mathrm{m}$

Figure 3: Histological sections of salivary glands of Rhipicephalus sanguineus females used as test group TG (SGE6). Baker technique. 
Citation: Furquim KCS, Camargo-Mathias MI, Hebling LMGF, Roma GC, Bechara GH (2014) Secretory Behavior of Salivary Glands of Rhipicephalus sanguineus Fed on Immunized Rabbit Hosts. J Cytol Histol S4: 012. doi:10.4172/2157-7099.S4-012
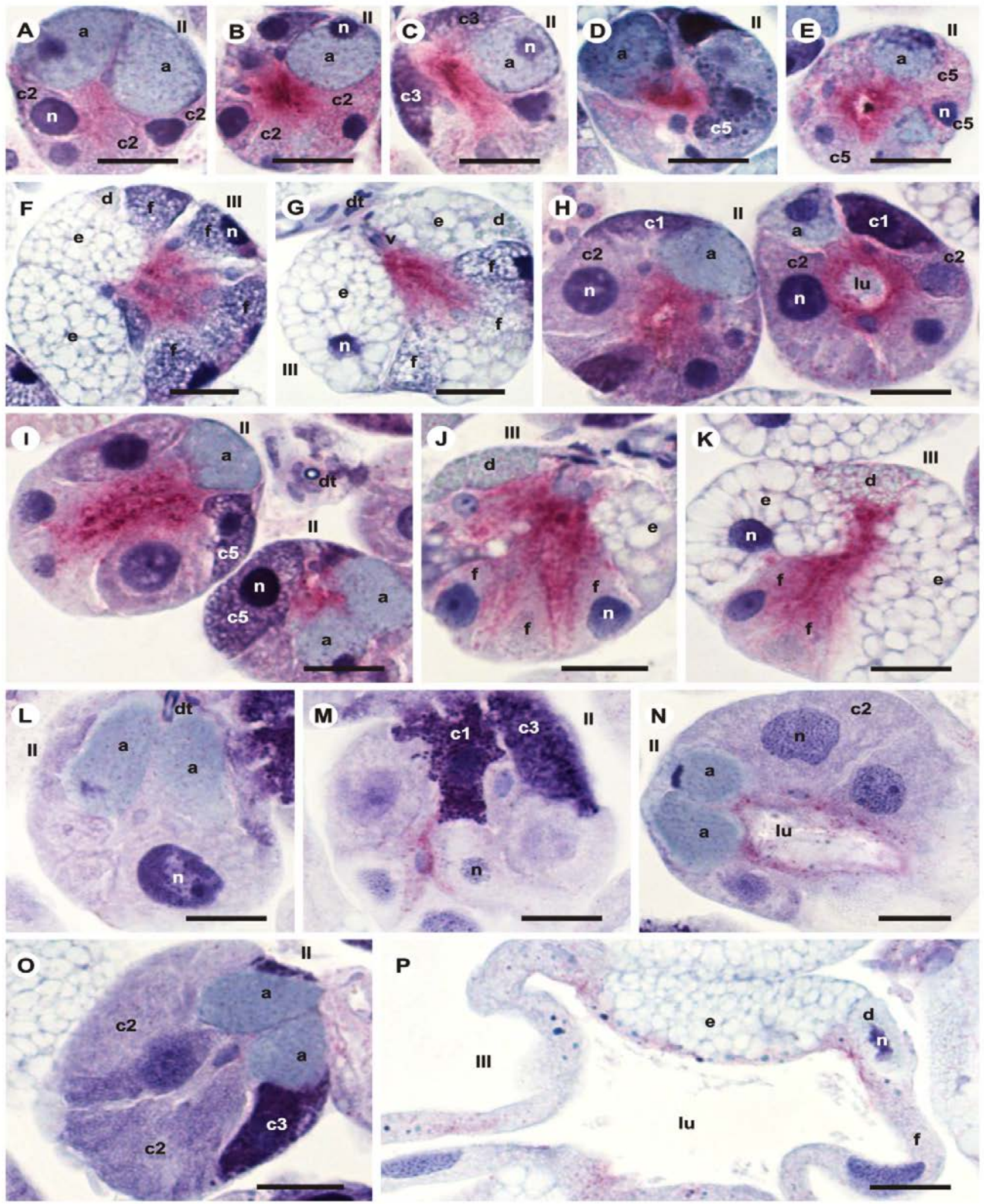

A-G: 2 days of feeding, $\mathbf{H}-\mathbf{K}: 4$ days of feeding, L-P: 6 days of feeding. II= acinus type II; III= acinus type III; $\mathbf{n =}$ nucleus; lu= acinus lumen; $\mathbf{d t}=$ ducto; $\mathbf{v}=\mathbf{v a l v e ;} \mathbf{a}=\mathbf{a}$ cell; $\mathbf{c} 1=\boldsymbol{c} \mathbf{1}$ cell; $\mathbf{c} 2=\boldsymbol{c} \mathbf{2}$ cell; $\mathbf{c} 3=\boldsymbol{c} \mathbf{3}$ cell; $\mathbf{c} 5=\boldsymbol{c} \mathbf{5}$ cell; $\mathbf{d}=\boldsymbol{d}$ cell; $\mathbf{e}=\mathbf{e}$ cell, $\mathbf{f}=\boldsymbol{f}$ cell. Bars: $25 \mu \mathrm{m}$

Figure 4: Histological sections of salivary glands of Rhipicephalus sanguineus females used as test group TG (SGE6). Acid phosphatase reaction and counterstained with hematoxylin. 
Citation: Furquim KCS, Camargo-Mathias MI, Hebling LMGF, Roma GC, Bechara GH (2014) Secretory Behavior of Salivary Glands of Rhipicephalus sanguineus Fed on Immunized Rabbit Hosts. J Cytol Histol S4: 012. doi:10.4172/2157-7099.S4-012

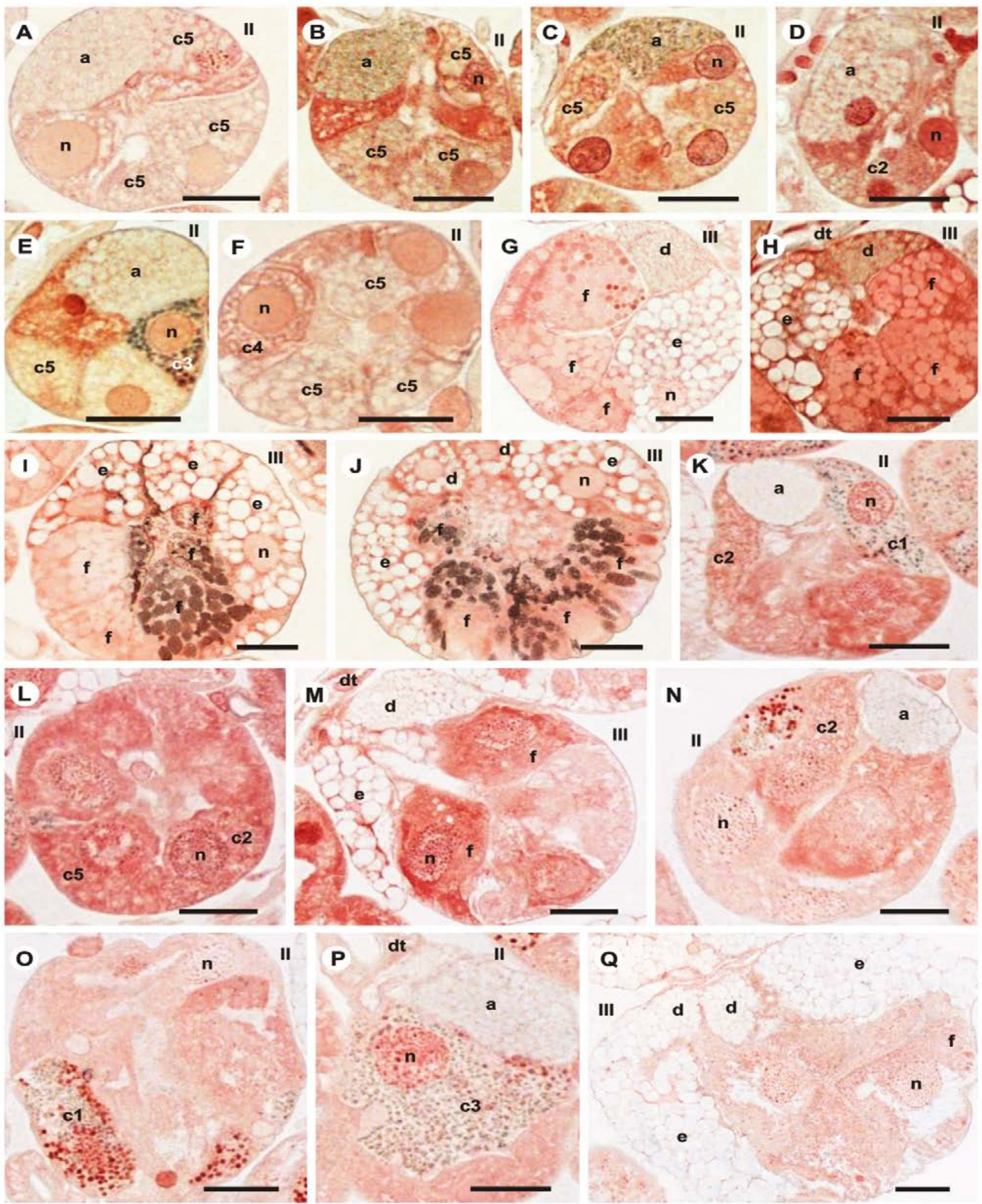

A-J: 2 days of feeding, K-M: 4 days of feeding, $\mathbf{N}-\mathbf{Q}: 6$ days of feeding, II= acinus type II; III= acinus type III; $\mathbf{n =}$ nucleus; $\mathbf{d t =}$ ducto; $\mathbf{a}=\mathbf{a}$ cell; $\mathbf{c} \mathbf{1}=\mathbf{c 1}$ cell; $\mathbf{c 2}=\mathbf{c 2}$ cell;

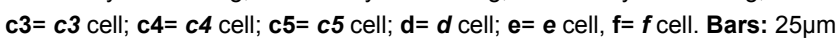

Figure 5: Histological sections of salivary glands of Rhipicephalus sanguineus females used as test group TG (SGE6). Von Kossa technique. 
stained for PAS; weakly (Figure 3C), moderately (Figure 3A, 3B and 3D) or strongly (Figure 3E) stained for Baker; negative (Figure 4D), weakly (Figure 4E) or moderately (Figure 4E) stained for acid phosphatase, and negative (Figure 5A, F) or weakly (Figure 5B, 5C and E) stained for von Kossa.

\section{Acinus III:}

- $\boldsymbol{d}$ cells: the granules are strongly stained for bromophenol blue (Figure 1D-G); negative for PAS (Figure 2E and 2F); moderately (Figure 3F, H-I) or strongly (Figure 3G) stained for Baker; negative for acid phosphatase (Figure $4 \mathrm{~F}$ and $4 \mathrm{G}$ ), and negative ure $5 \mathrm{G}$ and $5 \mathrm{~J}$ ) or moderately (Figure $5 \mathrm{H}$ ) stained for von Kossa.

- $\boldsymbol{e}$ cells: the granules are weakly (Figure $1 \mathrm{D}, 1 \mathrm{~F}$ and $1 \mathrm{G}$ ) or moderately (Figure 1E) stained for bromophenol blue; negative for PAS (Figure 2E-F); acid phosphatase (Figure $4 \mathrm{~F}-\mathrm{G}$ ) and von Kossa (Figure $5 \mathrm{G}-\mathrm{J}$ ), and weakly stained for Baker (Figure 3F-G, I).

- $f$ cells: the granules are weakly (Figure $1 \mathrm{~F}$ ) or moderately (Figure $1 G$ ) stained or even present heterogeneous staining (weak in one region and moderate in other) (Figure $1 \mathrm{E}$ ) for bromophenol blue; moderately (Figure 2F) or strongly (Figure 2E) stained for PAS; weakly (Figure EG), moderately (Figure 3H-I) or strongly (Figure 3G) stained for Baker and negative (Figure 5G-H), moderately (Figure 5I) or strongly (Figure 5J) stained for von Kossa. For acid phosphatase, the granules are weakly (Figure $4 \mathrm{~F}$ ) stained in the basal region of the cell, moderately (Figure $4 \mathrm{~F}$ ) in the apical and strongly (Figure $4 \mathrm{G}$ ) in the lumen.

\section{Females fed for 4 days}

\section{Acinus II:}

- $\boldsymbol{a}$ cells: the granules are weakly stained for bromophenol blue (Figure 1H-I); negative for PAS (Figure 2G-J), acid phosphatase (Figure $4 \mathrm{H}-\mathrm{I}$ ) and von Kossa (Figure 5K), and strongly stained for Baker (Figure 3J, L-M).

- $\boldsymbol{c 1}$ cells: the granules are strongly stained for bromophenol blue (Figure 1H), PAS (Figure 2G, I), Baker (Figure 3J-K) and von Kossa (Figure $5 \mathrm{~K}$ ) and negative for acid phosphatase (Figure $4 \mathrm{H}$ ).

- c2 cells: the granules are weakly stained for bromophenol blue (Figure 1I); moderately stained for PAS (Figure 2G-H); weakly (Figure $3 \mathrm{~J}$ ), moderately (Figure $3 \mathrm{~K}-\mathrm{L}$ ) or strongly (Figure $3 \mathrm{M}$ ) stained for Baker; weakly (Figure $4 \mathrm{H}$ ) or moderately (Figure $4 \mathrm{H}$ ) stained for acid phosphatase and negative for von Kossa (Figure 5K-L).

- $c 3$ cells: are not observed for being inactive.

- c4 cells: are not observed for being inactive.

- $\boldsymbol{c 5}$ cells: the granules are moderately stained for bromophenol blue (Figure 1J); moderately (Figure 2I) or strongly (Figure 2J) stained for PAS; weakly stained for acid phosphatase (Figure 4I); negative for von Kossa (Figure 5L) and present heterogeneous staining (moderate in one region and Strong in other) for Baker (Figure 3L).

\section{Acinus III:}

- $\boldsymbol{d}$ cells: the granules are weakly (Figure $1 \mathrm{~K}$ ) or moderately (Figure 1L) stained for bromophenol blue; negative (Figure $2 \mathrm{~K}$ ) or heterogeneous staining (negative in one region and weak in other region) (Figure 2L) for PAS; strongly stained for Baker (Figure $3 \mathrm{~N}$ $\mathrm{O}$ ); heterogeneous staining (negative in one region and weak in other region) for acid phosphatase (Figure 4J-K) and negative for von Kossa (Figure 5M).
- $\boldsymbol{e}$ cells: the granules are weakly stained for bromophenol blue (Figure 1K-L); negative for PAS (Figure 2K-L), acid phosphatase (Figure $4 \mathrm{~J}-\mathrm{K}$ ) and von Kossa (Figure $5 \mathrm{M}$ ) and weakly (Figure $3 \mathrm{~N}$ ) or moderately (Figure 3O) stained for Baker.

- $f$ cells: in this phase of the secretory cycle these cells no longer contain secretion granules (Figures $1 \mathrm{~K}, 1 \mathrm{~L}, 2 \mathrm{~K}, 2 \mathrm{~L}, 3 \mathrm{~N}, 4 \mathrm{~J}, 3 \mathrm{~K}$ and $5 \mathrm{M}$ ).

\section{Females fed for 6 days}

\section{Acinus II:}

- $\boldsymbol{a}$ cells: the granules are moderately stained for bromophenol blue (Figure $1 \mathrm{M}$ and $1 \mathrm{~N}$ ) and Baker (Figure 3P) and negative for PAS (Figure $2 \mathrm{M}-\mathrm{O}$ ), acid phosphatase (Figure $4 \mathrm{~L}, 4 \mathrm{~N}$ and $4 \mathrm{O}$ ) and von Kossa (Figure $5 \mathrm{~N}$ and $\mathrm{P}$ ).

- $\boldsymbol{c 1}$ cells: the granules are moderately stained for bromophenol blue (Figure $1 \mathrm{M}$ ) and von Kossa (Figure 5O); strongly stained for PAS (Figure $2 \mathrm{~N}$ ) and Baker (Figure 3P) and negative for acid phosphatase (Figure 4M).

- $\boldsymbol{c} 2$ cells: the granules are weakly stained for bromophenol blue (Figure $1 \mathrm{~N}$ ); weakly (Figures $2 \mathrm{O}$ and $3 \mathrm{Q}$ ) or moderately ((Figures $2 \mathrm{M}$ and 3P-Q) stained for PAS and Baker; negative (Figure $4 \mathrm{~N}$ ) or weakly (Figure 4O) stained for acid phosphatase and negative for von Kossa (Figure $5 \mathrm{~N}$ ).

- c3 cells: the granules are moderately stained for bromophenol blue (Figure $1 \mathrm{M}$ ) and von Kossa (Figure 5P); strongly stained for PAS (Figure $\mathrm{M}-\mathrm{O}$ ) and Baker (Figure $3 \mathrm{Q}$ ) and negative for acid phosphatase (Figure 4M).

- $c 4$ cells: it was not possible to observe these cells in this feeding phase through the techniques applied.

- $c 5$ cells: are not observed for being inactive in this phase.

\section{Acinus III:}

- $\boldsymbol{d}$ cells: the granules are strongly stained for bromophenol blue (Figure 1O); negative for PAS (Figure 2P), acid phosphatase (Figure 4P) and von Kossa (Figure 5Q) and moderately stained for Baker (Figure $3 R)$.

- $\boldsymbol{e}$ cells: the granules are weakly stained for bromophenol blue (Figure 1O); negative for PAS (Figure 2P), acid phosphatase (Figure $4 \mathrm{P}$ ) and von Kossa (Figure 5Q); and weakly (Figure 3S) or moderately (Figure 3R) stained for Baker.

- $f$ cells: in this phase of the secretory cycle these cells no longer contain secretion granules (Figure 1O, 2P, 3S, 4P, 5Q).

The results for salivary glands of the females from groups CG and TG fed for 2, 4 and 6 days are summarized in Tables 1-8.

\section{Discussion}

In this study, a histochemical analysis of the salivary glands of $R$. sanguineus females fed for 2, 4 and 6 days in hosts previously immunized with the glandular extract obtained from salivary glands of females of the same species fed for 6 days (SGE6) was performed, with the objective to detect alterations in the secretory cycle of glycoproteins, lipoproteins, phosphatase and calcium, commonly present in the saliva of these individuals.

Considering the results obtained it was verified that the ticks' feeding on host immunized with SGE6 extract affected the secretory behavior of the gland, corroborating [28], who verified that the pharmacology of 
Citation: Furquim KCS, Camargo-Mathias MI, Hebling LMGF, Roma GC, Bechara GH (2014) Secretory Behavior of Salivary Glands of Rhipicephalus sanguineus Fed on Immunized Rabbit Hosts. J Cytol Histol S4: 012. doi:10.4172/2157-7099.S4-012

Page 9 of 12

\begin{tabular}{|c|c|c|c|c|c|c|c|c|c|c|c|}
\hline & & \multicolumn{10}{|c|}{ Study Groups } \\
\hline & & \multicolumn{5}{|c|}{ CG } & \multicolumn{5}{|c|}{ TG } \\
\hline & & BB & PAS & B & AP & VK & BB & PAS & B & AP & VK \\
\hline Acini & Cells & & & & & & & & & & \\
\hline \multirow{6}{*}{ II } & $a$ & (2) 3 & (2) & B & 0 & 0 & 2 & $\mathbf{0} ; \mathbf{0}$ & (2) & 0 & $\mathbf{0} ; \mathbf{0}$ \\
\hline & $c 1$ & (3) & (3) & (3) & $\phi$ & (3) & * & $*$ & * & * & $*$ \\
\hline & $c 2$ & (0) & $\mathbf{0}$ & - & (2) & 0 & - & (2) & D & $\mathbf{0} ; \mathbf{2}$ & 0 \\
\hline & $c 3$ & 2 & (3) & B & & $\mathbf{0} ; \mathbf{3}$ & (2) & (3) & (3) & 2 & \\
\hline & $c 4$ & 0 & 0 & 0 & & 0 & o & 0 & o & $\phi$ & 0 \\
\hline & $c 5$ & D; 2 & $\mathbf{0} ; \mathbf{2}$ & 2; & 2 & 0 & - & $\mathbf{0}$ & -; 2 ; 3 & $\mathbf{0} ; \mathbf{0} ; \mathbf{0}$ & $\mathbf{0} ; \mathbf{0}$ \\
\hline \multirow{3}{*}{ III } & $d$ & 3; 4 & 0 & 3 & o & 0 & 3; 9 & 0 & 2; 3 & o & $\mathbf{0}$ \\
\hline & e & $\mathbf{0} ; 2$ & 0 & 2 & 0 & 0 & $\mathbf{o}$ & 0 & 0 & 0 & 0 \\
\hline & $f$ & (); 2 & 2; 3 & ; 3 & (); 2 & & D; 2 & 2; 3 & D; 2 ; 3 & D; 2 & 0; $2 ; 3$ \\
\hline
\end{tabular}

The results for the salivary glands females fed for 2,4 and 6 days from the CG were presented in the study by Furquim et al. (submitted paper). BB: bromophenol; PAS: PAS; B: Baker; AP: phosphatase; VK: von Kossa; *: inactive cell; $\phi$ : not observed cell; the intensity of staining varied from $\mathbf{0}-\mathbf{4}$, being: $\mathbf{0}$ : negative and $\mathbf{4}$ : strongly positive.

Table 1: Histochemistry of the glandular acini secretion of $R$. sanguineus females from groups CG and TG fed for 2 days.

\begin{tabular}{|c|c|c|c|c|c|c|c|c|c|c|c|}
\hline & & \multicolumn{10}{|c|}{ Study Groups } \\
\hline & & \multicolumn{5}{|c|}{ CG } & \multicolumn{5}{|c|}{ TG } \\
\hline & & BB & PAS & B & AP & VK & BB & PAS & B & AP & VK \\
\hline Acini & Cells & & & & & & & & & & \\
\hline \multirow{6}{*}{ II } & $a$ & $\mathbf{0} ; 2$ & 0 & 3 & 0 & 0 & (1) & 0 & 3 & 0 & 0 \\
\hline & $c 1$ & 2 & 3 & $\phi$ & 0 & 3 & 3 & & 3 & 0 & 3 \\
\hline & $c 2$ & (1) & 2 & $\phi$ & & 0 & (1) & 2 & $\mathbf{0} ; \mathbf{2} ; \mathbf{3}$ & $\mathbf{0}$ & 0 \\
\hline & $c 3$ & 2 & 3 & 3 & 0 & 0; 3 & * & * & * & * & * \\
\hline & $c 4$ & 0 & 0 & (1) & $\mathbf{0} ; \mathbf{0}$ & 0 & * & * & * & * & * \\
\hline & $c 5$ & 2 & $\mathbf{0} ; 2$ & $\phi$ & & 0 & 2 & 2) & 2; & (1) & 0 \\
\hline \multirow{2}{*}{ III } & $d$ & 2 & 0 & 3 & 0 & 0 & $\mathbf{0} ; 2$ & $\mathbf{0} ; \mathbf{0}$ & 3 & $\mathbf{0} ; \mathbf{0}$ & 0 \\
\hline & e & D & o & 2 & & 0 & D & o & $\mathbf{0}$ & 0 & 0 \\
\hline
\end{tabular}

The results for the salivary glands females fed for 2, 4 and 6 days from the CG were presented in the study by Furquim et al. (submitted paper). BB: bromophenol; PAS: PAS; B: Baker; AP: phosphatase; VK: von Kossa; *: inactive cell; $\phi$ : not observed cell; the intensity of staining varied from $\mathbf{0}-\mathbf{4}$, being: $\mathbf{0}$ : negative and $\mathbf{4}$ : strongly positive.

Table 2: Histochemistry of the glandular acini secretion of $R$. sanguineus females from groups $\mathbf{C G}$ and TG fed for 4 days.

\begin{tabular}{|c|c|c|c|c|c|c|c|c|c|c|c|}
\hline & & \multicolumn{10}{|c|}{ Study Groups } \\
\hline & & \multicolumn{5}{|c|}{ CG } & \multicolumn{5}{|c|}{ TG } \\
\hline & & BB & PAS & B & AP & VK & BB & PAS & B & AP & VK \\
\hline Acini & Cells & & & & & & & & & & \\
\hline \multirow{6}{*}{ II } & $a$ & (); 2 & 0 & 3 & 0 & 0 & 2 & 0 & 2 & 0 & 0 \\
\hline & $c 1$ & 2 & 3 & 3 & 0 & 0 & 2 & 3 & & 0 & 2 \\
\hline & $c 2$ & (1) & 2 & 2 & (1) & 0 & (1) & $\mathbf{0} ; 2$ & $\mathbf{0} ; 2$ & $\mathbf{0} ; \mathbf{0}$ & 0 \\
\hline & $c 3$ & 2 & 3 & 3 & 0 & 2 & 2 & 3 & 3 & 0 & \\
\hline & $c 4$ & 0 & 0 & 0 & 0 & 0 & & $\phi$ & $\phi$ & $\phi$ & $\phi$ \\
\hline & $c 5$ & * & $*$ & * & $*$ & * & * & * & * & * & * \\
\hline \multirow{2}{*}{ III } & $d$ & 2; 3 & 0 & 3 & 0 & 0 & 3 & 0 & 2 & 0 & 0 \\
\hline & e & (1) & 0 & 2 & & 0 & D & 0 & $\mathbf{0}$ & 0 & 0 \\
\hline
\end{tabular}

The results for the salivary glands females fed for 2,4 and 6 days from the CG were presented in the study by Furquim et al. (submitted paper). BB: bromophenol; PAS: PAS; B: Baker; AP: phosphatase; VK: von Kossa; *: inactive cell; $\phi$ : not observed cell; the intensity of staining varied from $\mathbf{0}-\mathbf{4}$, being: $\mathbf{0}$ : negative and $\mathbf{4}$ : strongly positive.

Table 3: Histochemistry of the glandular acini secretion of $R$. sanguineus females from groups $\mathbf{C G}$ and TG fed for 6 days.

the ticks' saliva could be molded according to the specific haemostatic defenses of the host, as the composition of the saliva would undergo variations in the composition throughout the glandular cycle [12-14, 17, 29-31], satisfying the ectoparasite's needs in the modulation of the immune-inflammatory and hemostatic systems of the host. The data here obtained demonstrated that the hosts of TG group developed resistance to the glandular antigens present in SGE6 extract used in the inoculation.

In this study a comparison of histochemical data from different periods of the secretory cycle (2, 4 and 6 days) of glands from TG group 
Citation: Furquim KCS, Camargo-Mathias MI, Hebling LMGF, Roma GC, Bechara GH (2014) Secretory Behavior of Salivary Glands of Rhipicephalus sanguineus Fed on Immunized Rabbit Hosts. J Cytol Histol S4: 012. doi:10.4172/2157-7099.S4-012

Page 10 of 12

\begin{tabular}{|c|c|c|c|c|c|c|c|}
\hline & & \multicolumn{6}{|c|}{ Study Groups } \\
\hline & & \multicolumn{3}{|c|}{ CG } & \multicolumn{3}{|c|}{ TG } \\
\hline & & 2 days of feeding & 4 days of feeding & 6 days of feeding & 2 days of feeding & 4 days of feeding & 6 days of feeding \\
\hline Acini & Cells & & & & & & \\
\hline \multirow{6}{*}{ II } & $a$ & 2; 3 & $\mathbf{0} ; 2$ & $\mathbf{0} ; 2$ & 2 & (1) & 2 \\
\hline & $c 1$ & 3 & 2 & 2 & * & 3 & 2 \\
\hline & $c 2$ & (1) & (1) & (1) & (1) & (1) & (1) \\
\hline & $c 3$ & 2 & 2 & 2 & 2 & $*$ & 2 \\
\hline & $c 4$ & 0 & 0 & 0 & 0 & * & * \\
\hline & $c 5$ & $\mathbf{0}$ & 2 & $*$ & D & 2 & * \\
\hline \multirow{3}{*}{ III } & $d$ & 3 & 2 & 2; 3 & 3; 4 & $\mathbf{0} ; 2$ & 3 \\
\hline & e & $\mathbf{0} ; 2$ & D & - & $\mathbf{0} ; 2$ & D & D \\
\hline & $f$ & $\mathbf{0} ; 2$ & - & - & $\mathbf{0} ; 2$ & - & - \\
\hline
\end{tabular}

The results for the salivary glands females fed for 2,4 and 6 days from the $\mathbf{C G}$ were presented in the study by Furquim et al. (submitted paper). *: inactive cell; $\_$: no secretion granules; the intensity of staining varied from $\mathbf{0 - 4}$, being: $\mathbf{0}$ : negative and $\mathbf{4}$ : strongly positive.

Table 4: Protein staining for acini II and III of salivary glands of $R$. sanguineus females from groups CG and TG fed for 2,4 and 6 days.

\begin{tabular}{|c|c|c|c|c|c|c|c|}
\hline & & \multicolumn{6}{|c|}{ Study Groups } \\
\hline & & \multicolumn{3}{|c|}{ CG } & \multicolumn{3}{|c|}{ TG } \\
\hline & & 2 days of feeding & 4 days of feeding & 6 days of feeding & 2 days of feeding & 4 days of feeding & 6 days of feeding \\
\hline Acini & Cells & & & & & & \\
\hline \multirow{6}{*}{ II } & $a$ & (1) & $\boldsymbol{0}$ & 0 & $\mathbf{0} ; \mathbf{0}$ & 0 & $\boldsymbol{0}$ \\
\hline & $c 1$ & 3 & 3 & 3 & * & 3 & 3 \\
\hline & $c 2$ & (); 2 & 2 & 2 & 2 & 2 & $\mathbf{0} ; 2$ \\
\hline & $c 3$ & 3 & 3 & 3 & 3 & $*$ & 3 \\
\hline & $c 4$ & 0 & 0 & 0 & 0 & * & $\phi$ \\
\hline & $c 5$ & $\mathbf{0} ; 2$ & (); 2 & * & $\mathbf{0} ; 2$ & 2; 3 & * \\
\hline \multirow{3}{*}{ III } & $d$ & 0 & 0 & 0 & 0 & 0; $\mathbf{0}$ & 0 \\
\hline & e & 0 & $\boldsymbol{0}$ & 0 & O & 0 & 0 \\
\hline & $f$ & 2; 3 & - & - & 2; 3 & - & - \\
\hline
\end{tabular}

The results for the salivary glands females fed for 2,4 and 6 days from the CG were presented in the study by Furquim et al. (submitted paper). ${ }^{*}$ inactive cell; $\phi$ : not observed cell; __. no secretion granules; the intensity of staining varied from $\mathbf{0 - 4}$, being: $\mathbf{0}$ : negative and $\mathbf{4}$ : strongly positive.

Table 5: Polysaccharides staining for acini II and III of salivary glands of $R$. sanguineus females from groups CG and TG fed for 2,4 and 6 days.

\begin{tabular}{|c|c|c|c|c|c|c|c|}
\hline & & \multicolumn{6}{|c|}{ Study Groups } \\
\hline & & \multicolumn{3}{|c|}{ CG } & \multicolumn{3}{|c|}{ TG } \\
\hline & & 2 days of feeding & 4 days of feeding & 6 days of feeding & 2 days of feeding & 4 days of feeding & 6 days of feeding \\
\hline Acini & Cells & & & & & & \\
\hline \multirow{6}{*}{ II } & $a$ & 3 & 3 & 3 & 2 & 3 & 2 \\
\hline & $c 1$ & 3 & $\phi$ & 3 & * & 3 & 3 \\
\hline & $c 2$ & (1) & $\phi$ & 2 & (1) & (); $2 ; 3$ & (); 2 \\
\hline & c3 & 3 & 3 & 3 & 3 & * & 3 \\
\hline & $c 4$ & 0 & (1) & 0 & 0 & $*$ & $\phi$ \\
\hline & $c 5$ & 2; 3 & $\phi$ & * & $\mathbf{0} ; \mathbf{2} ; \mathbf{3}$ & 2; 3 & * \\
\hline \multirow{3}{*}{ III } & $d$ & 3 & 3 & 3 & 2; 3 & 3 & 2 \\
\hline & e & 2 & 2 & 2 & (1) & $\mathbf{0} ; 2$ & $\mathbf{0} ; 2$ \\
\hline & $f$ & 2; 3 & - & - & $\mathbf{0} ; \mathbf{2} ; \mathbf{3}$ & - & - \\
\hline
\end{tabular}

The results for the salivary glands females fed for 2,4 and 6 days from the CG were presented in the study by Furquim et al. (submitted paper).*: inactive cell; $\phi$ : cell not observed; _. : no secretion granules; the intensity of staining varied from $\mathbf{0 - \mathbf { 4 }}$, being: $\mathbf{0}$ : negative and $\mathbf{4}$ : strongly positive.

Table 6: Lipids staining for acini II and III of salivary glands of $R$. sanguineus females from groups CG and TG fed for 2, 4 and 6 days.

was made and alterations between one period and another in relation to the same comparison made in CG group were verified. In this sense, in CG group a gradual reduction in the components as the feeding process progressed was observed, except for calcium and proteins which remained unaltered in 4-day glands, in relation to the 2-day glands; and in the 6-day glands in relation to the 4-day ones, respectively. In TG group the glands of females fed for 4 days, compared with the ones fed for 2 days, presented a reduction in proteins, acid phosphatase and calcium; and the glands of females fed for 6 days, compared with ones fed for 4 days, showed a reduction in polysaccharides, lipids and acid phosphatase. This glandular 
Citation: Furquim KCS, Camargo-Mathias MI, Hebling LMGF, Roma GC, Bechara GH (2014) Secretory Behavior of Salivary Glands of Rhipicephalus sanguineus Fed on Immunized Rabbit Hosts. J Cytol Histol S4: 012. doi:10.4172/2157-7099.S4-012

Page 11 of 12

\begin{tabular}{|c|c|c|c|c|c|c|c|}
\hline & & \multicolumn{6}{|c|}{ Study Groups } \\
\hline & & \multicolumn{3}{|c|}{ CG } & \multicolumn{3}{|c|}{ TG } \\
\hline & & 2 days of feeding & 4 days of feeding & 6 days of feeding & 2 days of feeding & 4 days of feeding & 6 days of feeding \\
\hline Acini & Cells & & & & & & \\
\hline \multirow{6}{*}{ II } & $a$ & 0 & 0 & 0 & 0 & 0 & 0 \\
\hline & c1 & $\phi$ & 0 & 2 & * & 0 & 0 \\
\hline & $c 2$ & 2 & 2 & (1) & $\mathbf{0} ; 2$ & o & 0; $\mathbf{0}$ \\
\hline & c3 & 2 & 0 & 0 & 2 & * & 0 \\
\hline & $c 4$ & 2 & $\mathbf{0} ; \mathbf{0}$ & 0 & $\phi$ & * & $\phi$ \\
\hline & $c 5$ & 2 & 2 & * & $\mathbf{0} ; \mathbf{0} ; \mathbf{2}$ & (1) & * \\
\hline \multirow{3}{*}{ III } & $d$ & 0 & 0 & 0 & 0 & 0; $\mathbf{0} ; \mathbf{2}$ & 0 \\
\hline & e & 0 & 0 & 0 & 0 & 0 & 0 \\
\hline & $f$ & (); 2 & - & - & $\mathbf{0} ; 2$ & - & - \\
\hline
\end{tabular}

The results for the salivary glands females fed for 2,4 and 6 days from the CG were presented in the study by Furquim et al. (submitted paper).*: inactive cell; $\phi$ : cell not observed; _. : no secretion granules; the intensity of staining varied from $\mathbf{0}-\mathbf{4}$, being: $\mathbf{0}$ : negative and $\mathbf{4}$ : strongly positive.

Table 7: Acid phosphatase staining for acini II and III of salivary glands of $R$. sanguineus females from groups CG and TG fed for 2, 4 and 6 days.

\begin{tabular}{|c|c|c|c|c|c|c|c|}
\hline & & \multicolumn{6}{|c|}{ Study Groups } \\
\hline & & \multicolumn{3}{|c|}{ CG } & \multicolumn{3}{|c|}{ TG } \\
\hline & & 2 days of feeding & 4 days of feeding & 6 days of feeding & 2 days of feeding & 4 days of feeding & 6 days of feeding \\
\hline Acini & Cells & & & & & & \\
\hline \multirow{6}{*}{ II } & $a$ & 0 & 0 & $\boldsymbol{0}$ & $\mathbf{0} ; \mathbf{0} ; 2$ & 0 & 0 \\
\hline & $c 1$ & 3 & 3 & 0 & * & 3 & 2 \\
\hline & c2 & 0 & 0 & 0 & 0 & 0 & 0 \\
\hline & c3 & $\mathbf{0} ; 3$ & 0; 3 & 2 & 3 & * & 2 \\
\hline & $c 4$ & 0 & o & 0 & 0 & * & $\phi$ \\
\hline & $c 5$ & 0 & 0 & * & $\mathbf{0} ; \mathbf{0}$ & 0 & * \\
\hline \multirow{3}{*}{ III } & $d$ & 0 & 0 & 0 & $\mathbf{0} ; \mathbf{0}$ & 0 & 0 \\
\hline & e & 0 & 0 & 0 & 0 & o & 0 \\
\hline & $f$ & 0 & - & - & 0; 2; 3 & - & - \\
\hline
\end{tabular}

Table 8: Calcium staining for acini II and III of salivary glands of $R$. sanguineus females from groups CG and TG fed for 2,4 and 6 days.

behavior could be explained by the parasite-immunized host relationship; i.e., the ectoparasites responded modifying the composition of their saliva according to the immunologic response of the host, which in this case developed resistance against the antigens present in SGE6 extract.

As for the histochemical alterations detected in each specific period of the secretory cycle (2, 4 or 6 days) in TG group, it was observed that in the glands of females fed for 2 days there was an increase in calcium, reduction of lipids and acid phosphatase and the intensity of staining for proteins and polysaccharides remained unaltered. In those fed for 4 days there was mainly a reduction in the staining of components, except for polysaccharides, which increased; and calcium, which remained unaltered. In those fed for 6 days a reduction in the components was also detected, except for proteins and calcium, which increased. This showed that the immunization with SGE6 glandular extract caused histochemical alterations in the glandular secretion, which would be mainly related to the reduction of the component contents here analyzed.

As for the cellular types, in a decrescent order of alterations, the most affected cells were: as $c 5 ; a, f ; d ; c 2$; and $c 3, e$ in the females fed for 2 days; $d ; c 5 ; a, c 1, c 2, e$ in the females fed for 4 days; and $c 2 ; a, c 1, d ; e$ in the females fed for 6 days. According to literature $a$ and $d$ cells would be responsible for the synthesis of lipoproteins which form the cement [29], in addition to proteins, from which some would be antigenic [32], and would act both in modulation of the host and the formation and maintenance of the feeding lesion [30]. The secretions synthetized by $c$ and $\boldsymbol{f}$ cells would be involved in the modulation of the local hemostatic reactions of the host [29,33-34] and the glycoproteins produced by $\boldsymbol{c}$ cells would act as anticoagulants [34].

In this sense, concerning the secretions of the most affected cells it can be inferred that those synthetized by $a, c 2$ and $d$ cells would present high immunologic capability when introduced in the host through inoculation of SGE6 extract, once this extract presented different biochemical and pharmacological characteristics from any other extract from other periods of the secretory cycle. This has probably occurred due to the quantitative and qualitative variation of its molecules [27]. However, for the secretory behavior of $c 5$ and $f$ cells, a possible explanation would rely on the importance of their secretion to the initial modulation of the immune-inflammatory and hemostatic systems of the host, and not to its immunogenicity, a hypothesis based on the fact that the hosts considered have not been previously immunized with the antigens from $c 5$ and $f$ cells, as they were not active in the glands of females fed for 6 days (glandular tissue used in the production of SGE6 extract), demonstrating that the hosts could not produce antibodies against these antigens.

In addition to this, it was verified that the components of the glandular secretion which underwent the most alterations were the lipids, followed by proteins, polysaccharides/acid phosphatase and 
Citation: Furquim KCS, Camargo-Mathias MI, Hebling LMGF, Roma GC, Bechara GH (2014) Secretory Behavior of Salivary Glands of Rhipicephalus sanguineus Fed on Immunized Rabbit Hosts. J Cytol Histol S4: 012. doi:10.4172/2157-7099.S4-012

calcium. According to literature, the lipid elements present in the ticks' saliva would be in the form of prostaglandins [4,13,35-36], purine nucleoside adenosine [36] and prostaciclins [37], molecules which would be part of the sophisticated pharmacologic arsenal for the modulation of the local hemostatic reactions in the host, which actuation would affect the ectoparasite's capability to remains attached and consuming blood [8]. This could explain why the lipid staining was the one which presented the most modifications in this study.

The data presented above confirm that the most pronounced alterations occurred in the glands of females fed for 2 days, and the alterations in 4-day and 6-day glands were less intense. The information provided here is quite inusitate, once it was expected that the most affected glandular tissue would be the one obtained from females fed for 6 days, once antigens from this tissue were inoculated on the hosts ( SGE6 extract). Such information confirms the hypothesis that the hosts would respond differently due to the qualitative and quantitative variation of the antigens inoculated in them [27] and, in this sense, the immunization with SGE6 extract stimulated in the hosts the development of an immune response mainly against the salivary antigens of females fed for 2 days, where the most pronounced histochemical alterations occurred.

\section{Acknowledgments}

This research has been supported by FAPESP (Fundação de Amparo à Pesquisa do Estado de São Paulo) (Grants no. 08/58443-7 and 07/59020-0) and CNPq (Conselho Nacional de Desenvolvimento Científico e Tecnológico) (Grant no. 308733/2006-1 and M.I. Camargo-Mathias and G.H. Bechara academic carrier research fellowships). Part of this work has been facilitated through the Integrated Consortium on Ticks and Tick-borne Diseases (ICTTD-3) supported by the European Union under contract number 510561-INCO.

\section{References}

1. Ribeiro JM, Makoul GT, Levine J, Robinson DR, Spielman A (1985) Antihemostatic, antiinflammatory, and immunosuppressive properties of the saliva of a tick, Ixodes dammini. J Exp Med 161: 332-344.

2. Brossar M, Wikel SK (2004) Tick immunobiology. Parasitology 129: S161-S176.

3. Mans BJ, Neitz AW (2004) Adaptation of ticks to a blood-feeding environment: evolution from a functional perspective. Insect Biochem Mol Biol 34: 1-17.

4. Steen NA, Barker SC, Alewood PF (2006) Proteins in the saliva of the Ixodida (ticks): pharmacological features and biological significance. Toxicon 47: 1-20.

5. Maritz-Olivier C, Stutzer C, Jongejan F, Neitz AW, Gaspar AR (2007) Tick antihemostatics: targets for future vaccines and therapeutics. Trends Parasitol 23: 397-407

6. Dantas-Torres F (2008) The brown dog tick, Rhipicephalus sanguineus (Latreille, 1806) (Acari: Ixodidae): from taxonomy to control. Vet Parasitol 152: 173-185.

7. Kazímirová M (2008) Pharmacologically active compounds in tick salivary glands In: Advances in Arachnology and Developmental Biology, Institute of Zoology, Belgrade.

8. Francischetti IM, Sa-Nunes A, Mans BJ, Santos IM, Ribeiro JM (2009) The role of saliva in tick feeding. Front Biosci (Landmark Ed) 14: 2051-2088.

9. Wikel SK (1999) Tick modulation of host immunity: an important factor in pathogen transmission. Int J Parasitol 29: 851-859.

10. Singh SK, Girschick HJ (2003) Tick-host interactions and their immunological implications in rick-borne diseases. Curr Sci India, 85: 1284-1298.

11. Kovár L (2004) Tick saliva in anti-tick immunity and pathogen transmission. Folia Microbiol (Praha) 49: 327-336.

12. McSwain JL, Essenberg RC, Sauer JR (1982) Protein changes in the salivary glands of the female lone star tick, Amblyomma americanum, during feeding. J Parasitol 68: 100-106.

13. Shipley MM, Dillwith JW, Bowman AS, Essenberg RC, Sauer JR (1993) Changes in lipids of the salivary glands of the lone star tick, Amblyomma americanum, during feeding. J Parasitol 79: 834-842.
14. Sanders ML, Scott AL, Glass GE, Schwartz BS (1996) Salivary gland changes and host antibody responses associated with feeding of male lone star ticks (Acari:Ixodidae). J Med Entomol 33: 628-634.

15. Kaufman WR (1989) Tick-host interaction: a synthesis of current concepts Parasitol Today 5: 47-56.

16. Furquim KC, Mathias MI, Hebling LM, Roma GC, Bechara GH (2011) Ticks' response to feeding on host immunized with glandular extracts of Rhipicephalus sanguineus females fed for 2,4 , and 6 days. I. Inactivity or early degeneration of salivary glands? Parasitol Res 109: 147-162.

17. Camargo-Matias MI, Furquim KCS (2013) The histology as a tool for the understanding of the morphophysiology of the brown dog tick (Rhipicephalus sanguineus) In: Advances in zoology research, Nova Science Publishers, New York.

18. Bechara GH, Szabó MPJ, Ferreira BR, Garcia MV (1995) Rhipicephalus sanguineus tick in Brazil: feeding and reproductive aspects under laboratorial conditions. Rev Bras Parasitol Vet 4: 61-66.

19. Sedmak JJ, Grossberg SE (1977) A rapid, sensitive, and versatile assay for protein using Coomassie brilliant blue G250. Anal Biochem 79: 544-552.

20. Pearse AGE (1985) Histochemistry. Theoretical and Applied. Analytic Technology, Churchill Livingston, New York.

21. McMANUS JF (1946) Histological demonstration of mucin after periodic acid Nature 158: 202

22. Junqueira LCU, Junqueira LMMS (1983) Técnicas básicas de citologia e histologia. Editora Santos, São Paulo.

23. Baker JR (1946) The histochemical recognition of lipine. Q J Microsc Sci 87: 441-470.

24. Hussein MA, Bowen ID, Lewis GH (1990) The histochemical localization of ATPase, cholinesterase and acid phosphatase activity in Culex pipiens (Diptera, Culicidae) larvae using a methacrylate embedding technique. Cell Biol Int Rep 14: 775-781.

25. McMullen HL, Sauer JR, Burton RL (1976) Possible role in uptake of water vapour by ixodid tick salivary glands. J Insect Physiol 22: 1281-1285.

26. Rudolph D, Knülle W (1978) Uptake of water vapour from air: process, site and mechanism in ticks In: Comparative Physiology: Water, lons and Fluid Mechanics, Cambridge University Press, Cambridge, USA.

27. Furquim KCS, Camargo-Mathias MI, Hebling LMGF, Roma GC, Bechara GH (2013) Alterations in the secretory behavior of salivary glands of Rhipicephalus sanguineus females (Latreille, 1806) (Acari: Ixodidae) feeding in resistant rabbit, Air Water Borne Diseases 2: 114

28. Ribeiro JM (1987) Role of saliva in blood-feeding by arthropods. Annu Rev Entomol 32: 463-478.

29. Binnington KC (1978) Sequential changes in salivary gland structure during attachment and feeding of the cattle tick, Boophilus microplus. Int J Parasitol 8: $97-115$.

30. Mulenga A, Blandon M, Khumthong $R$ (2007) The molecular basis of the Amblyomma americanum tick attachment phase. Exp Appl Acarol 41: 267-287.

31. Xiang F, Zhang J, Zhou Y, Li Z, Gong H, et al. (2009) Proteomic analysis of proteins in the salivary glands of the fed and unfed female tick Rhipicephalus haemaphysaloides. Agr Sci China 8: 121-127.

32. Sonenshine DE (1993) Biology of Ticks Oxford University Press, Oxford

33. Walker AR, Fletcher JD, Gill HS (1985) Structural and histochemical changes in the salivary glands of Rhipicephalus appendiculatus during feeding. Int $\mathrm{J}$ Parasitol 15: 81-100.

34. Sonenshine DE (1991) Biology of ticks. Oxford University Press, Oxford

35. Harris SG, Padilla J, Koumas L, Ray D, Phipps RP (2002) Prostaglandins as modulators of immunity. Trends Immunol 23: 144-150.

36. Oliveira CJ, Sá-Nunes A, Francischetti IM, Carregaro V, Anatriello E, et al. (2011) Deconstructing tick saliva: non-protein molecules with potent immunomodulatory properties. J Biol Chem 286: 10960-10969.

37. Ribeiro JM, Makoul GT, Robinson DR (1988) Ixodes dammini: evidence for salivary prostacyclin secretion. J Parasitol 74: 1068-1069. 